\title{
EN RECUERDO \\ DE MANUEL TUÑÓN DE LARA
}

GABRIEL TORTELLA

Universidad de Alcalá

El encargo que me ha hecho Pablo Martín Aceña de escribir esta nota me compensa, aunque sólo en parte, el dolor que me causó la inesperada noticia de la muerte de Manuel Tuñón de Lara, historiador a quien admiraba, amigo a quien quería. Pese a lo plateado de su cabellera, que sus compañeros habiamos ido viendo pasar gradualmente del gris al blanco, y lo creciente de su sordera, el vigor, la vivacidad, la inteligencia, el humor de Manolo Tuñón eran tales que uno olvidaba que, como todos, se iba haciendo mayor; ha muerto a los ochenta y un años, y para sus amigos la suya ha sido una muerte prematura.

Aunque hizo estudios de Derecho y Economía en Paris, Manuel Tuñon de Lara no era propiamente un historiador económico. Sin embargo tenia varias afinidades con los historiadores económicos que justifican que consideremos su pérdida como nuestra. En primer lugar, Tunón tenía una gran simpatía por la Historia económica; prestó, además, un apoyo entusiasta a la Revista cuando ésta se gestaba. En segundo lugar, Tuñón fue uno de los pioneros españoles de la aplicación de las ciencias sociales a la Historia. En tercer lugar, Tuñón se dirige a la Historia contemporánea con una serie de preguntas anotadas en su agenda, en busca de respuestas, haciendo buena la máxima de Marc Bloch de que «cada generación hace su propia historia». Para Tuñón, como para mí mismo - me di cuenta de esto hablando con ély para tantos otros, entre los que se contaba señaladamente Antonio Ramos Oliveira, en la Historia contemporánea debe estar la respuesta a los enigmas de la guerra civil, sus causas y sus consecuencias. Para Tunonn, que la vivió, el estudio de la Historia debía permitirnos comprender las peculiaridades so- 
ciales, económicas e institucionales que explicarian el desgarro absurdo y doloroso que fue la guerra civil.

Como para muchos otros jóvenes que estudiaban en la España franquista, lo primero que Tuñón de Lara significó para mí fue el ser autor de unos libros prohibidos de Historia que habia que procurarse por medios clandestinos: comprados en librerías españolas bajo cuerda, o traidos del extranjero burlando la vigilancia de los aduaneros. Y eran libros buenos, que satisfacian mi curiosidad, porque se planteaban esas preguntas que los libros permitidos no se hacian, porque analizaban los hechos sociales con mentalidad cientifica, porque no insultaban o descalificaban al adversario. La España del siglo XIX fue para mí, junto con la Historia de España del ya citado Ramos Oliveira, uno de los libros que definieron mi vocación de historiador económico. Seguí siendo lector asiduo de Tuñón de Lara más tarde en Estados Unidos, donde encontraba fácilmente sus obras, en francés o en español, en las bibliotecas. Por desgracia, Tuñón, al menos por entonces, apenas había sido traducido al inglés, por lo que no pude utilizarlo en mis clases alli como hubiera querido.

En una de mis vueltas a España, hacia 1970, tuve la suerte de conocer a Manuel Tuñón de Lara personalmente, y debi ese privilegio a mi padre, que se había convertido en su editor, al producir su Medio siglo de cultura española. Por indicación de mi padre, al que el propio Tuñón se lo habia sugerido, y en compañía de otros amigos como Elías Díaz y José Luis García Delgado, comencé a participar en los inolvidables coloquios de Pau, que rivalizan con su obra escrita como la más señalada contribución de Tunón a la Historia de España. Los coloquios de Pau fueron, creo yo, un hito en la historiografía española. Yo no llegué a ellos como novicio. Era ya profesor en Estados Unidos, estaba a punto de presentar mi tesis en la Universidad de Wisconsin, habia publicado algunas cosas, tenía años en universidades norteamericanas (amén de las españolas, pero de éstas había sacado muy poco). Sin embargo, en Pau aprendí mucho, casi todo de Manolo Tuñon, y el resto, gracias a Manolo Tuñón. Allí conocí a tantos historiadores que puede decirse que mi reencuentro con la historia española después de mi estancia en Estados Unidos tuvo lugar en Pau.

La idea de los «Coloquios de Pau» era como el huevo de Colón: organizar congresos anuales de Historia de España a pocos kilómetros de la frontera, con la libertad de las Universidades francesas (y con su apoyo), trabajando y discutiendo sin trabas policiales ni gubernamentales, pero sin sectarismos ni demagogias de políticos exiliados. Su existencia era una ayuda inapreciable para los historiadores demócratas o simplemente no adictos al franquismo; allí hacian lo que en la España de entonces no podian hacer: debatir en libertad; y 
además los «Coloquios» era una manera de inquietar a las autoridades franquistas y poner en evidencia la opresión ideológica y la inanidad científica del régimen dictatorial. Era una idea excelente, pero, como el huevo de Colón, había que haberla tenido y, además, habia que haberla llevado a cabo. $Y$ esa fue la idea de Tuñón, la obra que llevó a cabo magistralmente. Porque, además de lograr el apoyo entusiasta de las autoridades académicas de la Universidad de Pau, Manolo lograba llevar la batuta y marcar el tono entre un grupo numero. so y abigarrado de historiadores e hispanistas de ambos lados de la frontera, cada uno con sus idiosincrasias, sus fobias y sus filias, la mayoría gente de talento, sin duda, pero por lo mismo complicada. Manolo, con esa campechanía y ese humor que eran tan suyos, sabía ser firme y dejar muy claro el carácter académico de aquellos encuentros. Recuerdo que en una sesión plenaria un profesor de literatura, hombre muy notable, por desgracia desaparecido hace ya muchos años, se levantó impaciente y nos reprochó el estar discutiendo tecnicismos bizantinos mientras en España subsistia una dictadura a la que nuestro deber primero era denunciar. No se me olvidará la respuesta de Manolo: «Querido amigo: estamos dentro de la Universidad, y aqui se hace, o se intenta hacer, ciencia. Cuando acabemos la sesión, nos vamos a un bar o a mi casa, y alli firmamos los manifiestos que quieras. Pero aquí seguimos con los tecnicismos bizantinos.» Tenia toda la razón, por supuesto. Pero viniendo del «rojo» Tuñón, del único exiliado del coloquio (para quien, por añadidura, no entrañaba el menor riesgo lo que allí se firmara o dijera), aquella claridad y firmeza de ideas tenía doble o triple valor. $Y$ es que además de tener la razón desde el punto de vista ético, la tenía incluso desde el político. Porque si los «Coloquios de Pau» se hubieran convertido en un foro de denuncia política (denuncia para la que sin duda habia motivos sobrados en otros ámbitos), hubieran perdido inmediatamente su prestigio y, por tanto, su eficacia. Publicar un manifiesto de denuncia política de la dictadura desde los «Coloquios de Pau» hubiera sido el mejor servicio que hubiéramos podido hacer a esa misma dictadura. Además de ser un gran estudioso, Manolo tenia muy claras las realidades políticas.

Simpaticé personalmente con Tuñón de Lara desde el primer momento en que le vi. Era difícil sustraerse a su encanto personal. Aparte de su cabeza de actor de cine, tantas veces fotografiada y reproducida, su manera de hablar y de ser eran extraordinariamente simpáticas. Tenía una voz ligeramente ronca, y un leve deje andaluz, porque, a pesar de haber nacido en Madrid, su familia provenía de Jaén, y alli había pasado al menos parte de su infancia (creo recordar que decía: «Soy jiennense de Madrid»). Le encantaba trabajar — su obra lo demuestra - pero también charlar con los amigos: su conversación era chis- 
peante, lúcida, y llena de humor y de ironía. Se interesaba mucho por los demás; no se hacía ilusiones, pero eso no le quitaba de ser muy bondadoso. Tenía la sencillez y la elegancia del verdadero intelectual. Yo no sé si su simpatía por el comunismo le hizo ser dogmático o intransigente en algún momento. Yo vi todo lo contrario. Cuando me pidió que escribiera el capitulo sobre la economía del siglo XIX en la Historia de España que preparaba para Editorial Labor, quedé sorprendido; halagado también, pero más sorprendido. Crei mi deber advertirle que no iba a ser un texto marxista, que mi herramienta de trabajo era la economía que entonces llamaban algunos «convencional» $\mathrm{o}$ «burguesa», que yo estaba cerca de la «Nueva Historia Económica». Se echó a reír y me dijo que ya lo sabia, que nos conocíamos hacía años, que lo que quería era un texto de calidad (no sé si en eso no pecó de optimista), y que él no imponia líneas ideológicas.

Su obra abrió una nueva etapa en la historiografía contemporánea. Algunos de sus numerosos libros quedarán como modelos de buen hacer en la investigación histórica, especialmente en la aplicación de categorías sociológicas y politológicas al pasado. No soy quién para juzgar profesionalmente su obra completa, porque no labrábamos la misma parcela. Pero quiero traer a colación aquí un trabajo que, por haberse publicado en un periódico (El País), puede quedar olvidado y no lo merece. Me refiero a su análisis de las primeras elecciones españolas tras la dictadura de Franco, en 1977. En aquel artículo magistral mostraba Tuñón lo que puede hacer la Historia al servicio del análisis político. Ponia su autor de relieve las sorprendentes constantes del voto español, cuando, después de cuarenta años sin democracia, casi dos generaciones después de los últimos comicios, los nietos seguian votando de manera muy parecida a como lo habian hecho sus abuelos, como si el paréntesis dictatorial hubiera constituido unos «mal llamados cuarenta años» y la legalidad democrática de 1977 empalmara con la de 1936 sin más diferencia importante que la nada lamentable desaparición del anarquismo. Aquella página de periódico valia más que muchos ponderosos tomos.

La Historia ha perdido un maestro. Los que le conocíamos hemos perdido un maestro y un amigo. 